\title{
Late Results of Endoventricular Patch Plasty Repair in Akinetic and Dyskinetic Areas After Acute Myocardial Infarction
}

\author{
Paulo R. Prates, Abud Homsi Neto, Lucas Maynard Lovato, Guaracy F. Teixeira F', \\ João R. M. Sant'Anna, Luiz M. Yordi, Renato A. K. Kalil, Ivo A. Nesralla \\ Porto Alegre, RS - Brazil
}

\begin{abstract}
Objective - To assess the surgical results of endoventricular patch plasty repair in akinetic and dyskinetic left ventricular areas.

Methods - We studied 52 patients who had undergone endoventricular patch plasty repair associated with myocardial revascularization. The preoperative functional class distribution was as follows: class I in 1 (1.9\%) patient; class II in 2 (3.8\%) patients; class III in 23 (44.2\%) patients; and class IV in $26(50 \%)$ patients.
\end{abstract}

Results - The immediate mortality rate was $7.6 \%$ (4 patients). The clinical outcome of 44 patients followed up within a mean postoperative time of $29 \pm 25$ months was as follows: class I in 33 (75\%) patients; class II in 7 (15.9\%) patients; class III in 2 (4.5\%) patients; and class IV in 2 (4.5\%) patients. Comparison between pre-and postoperative catheterization in 21 patients showed that the ejection fraction increased from $46.3 \%$ to $51.3 \%(p=0.17)$; the left ventricular systolic volume decreased from $76.4 \mathrm{~mL}$ to $57.5 \mathrm{~mL},(p=0.078)$; and the left ventricular diastolic volume decreased from $141.2 \mathrm{~mL}$ to $105.8 \mathrm{~mL}$ ( $p=0.073$ ). These findings showed the tendency toward improvement, but with nonsignificant results.

Conclusion - The technique proved to be effective, to have a low mortality rate, to cause significant clinical improvement, an increase in ejection fraction, and a reduction in left ventricular volumes.

Keywords: ventricular aneurysm, ventricular dysfunction, cardiac surgery, hemodynamic assessment

Instituto de Cardiologia do Rio Grande do Sul/Fundação Universitária de Cardiologia

Mailing address: Paulo R. Prates - IC/FUC - Av. Princesa Isabel, 395 - 90620-001 Porto Alegre, RS, Brazil - E-mail: pesquisa@cardnet.tche.br

English version by Stela Maris C. e Gandour
An ischemic event may impair the interventricular septum with both akinetic and dyskinetic alterations. As that is not a resectable tissue, special techniques have been developed for its surgical treatment. In 1985, Cooley et al ${ }^{1}$ reported on the endoaneurysmorrhaphy technique for correcting left ventricular aneurysms, according to which aneurysms were more appropriately treated using a Dacron flap. Since 1991, we have been using this technique with preserved bovine pericardium, and our first results were published in 1991 and $1993^{2,3}$.

The incidence of left ventricular aneurysms after acute myocardial infarction depends on the diagnostic methods used. Studies based on clinical criteria and autopsy findings indicate an incidence ranging from $10 \%$ to $15 \%$. These data were obtained prior to thrombolytic therapy and angioplasty, and the impact of these types of treatment in the incidence of aneurysms remains unknown ${ }^{4}$.

Transmural myocardial infarction may cause early or late alterations in the left ventricular wall ${ }^{5}$. Dyskinesia represents the paradoxical movement of the infarction scar ${ }^{6}$ and is considered the true aneurysm. Akinesia represents the situation in which the scar remains motionless.

Both akinetic and dyskinetic segments may lead to chronic heart failure and a reduction in left ventricular ejection fraction throughout the years. Enlargement of the left ventricular cavity results in an increase in ventricular wall tension, causing an increase in the work of the residual healthy heart muscle. This results in ischemic distress, which, in the future, may lead to a reduction in systolic function ${ }^{7,8}$.

In true aneurysms, surgery has always been indicated in the presence of difficult to control heart failure, ventricular arrhythmias, angina refractory to clinical treatment, thromboembolism, or when the patients are referred for revascularization surgery ${ }^{3-9}$. Current studies have shown that early repair of both akinetic and dyskinetic areas after acute myocardial infarction prevents the impairment of healthy heart muscle, avoiding remodeling that leads to progressive dilation and the appearance of heart failure symptoms ${ }^{10}$. 
Both akinetic and dyskinetic alterations are treated with the use of endoaneurysmorrhaphy, and, in the cases of akinesia, endoventricular patch plasty repair is the most appropriate denomination for the technique. The literature ${ }^{11-13}$ shows that this is the most physiological manner of repairing the ventricular geometry, reconstructing the apex, and eliminating distension.

The objective of this study was to analyze early and late clinical results and also to hemodynamically assess endoaneurysmorrhaphy or endoventricular patch plasty repair in patients with left ventricular dysfunction and akinetic or dyskinetic areas. Clinical and hemodynamic data of the patients who died early and of those who survived were compared and revealed factors that influenced mortality.

\section{Methods}

From January 1991 to December 2000, 108 patients underwent endoaneurysmorrhaphy according to Cooley's technique ${ }^{1}$, using a flap of preserved bovine pericardium (fig. 1). The first 52 patients were studied.

Endoaneurysmorrhaphy surgery begins with a ventriculotomy at the left ventricular apex. Thrombi, when present in the cavity, are removed. The left ventricle is carefully inspected, and the precise transition zone between the fibrous and healthy myocardial tissue is identified.

A flap of bovine pericardium is molded according to the reconstitution of the left ventricular apex and sutured with Prolene 3.0 suture thread in the transition line between the fibrous and the healthy endocardial tissue, following the suture line adjacent to the interventricular septum, remodeling the apex.

Distortions present in the left ventricular apex and in its septum are excluded with this process, aiming at redu-

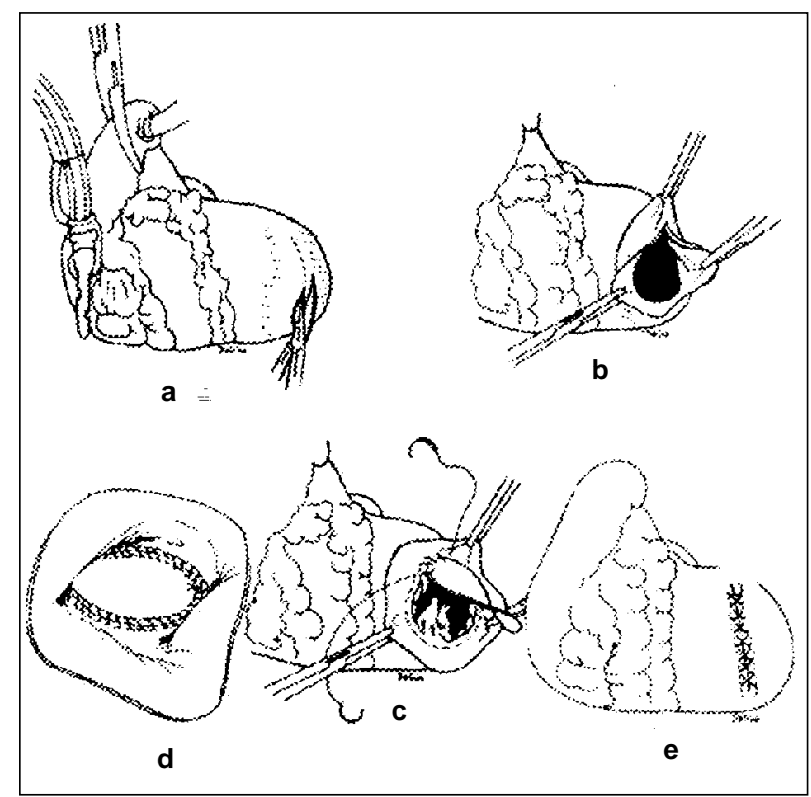

Fig. 1 - Technique of endoaneurysmorrhaphy by Cooley modified with the use of preserved bovine pericardium ${ }^{2}$. cing the left ventricular cavity, with a consequent reduction in ventricular wall pressure and reorganization of the healthy myocardial area. This leads to a reduction in cardiac work and oxygen consumption.

Then the ventriculotomy is sutured with Prolene 2.0 suture thread and myocardial revascularization is performed with mammary artery or saphenous vein bypass grafts, according to the need assessed during the catheterization prior to surgery.

In regard to the characteristics of our sample, we observed that the mean age of the patients was 58 years, the youngest was 35 and the oldest 76 . Of these 52 patients, 34 $(65.4 \%)$ were males and $18(34.6 \%)$ were females. The mean age for both sexes was 58 years. All patients had experienced a previous acute myocardial infarction, which resulted in left ventricular akinetic or dyskinetic alterations, or both. The preoperative functional class according to New York Heart Association (NYHA) criteria was as follows: class I in 1 $(1.9 \%)$ patient; class II in $2(3.8 \%)$ patients; class III in 23 (44.2\%) patients; and class IV in $26(50 \%)$ patients.

In regard to cardiopulmonary events prior to surgery, we observed 2 (3.8\%) patients with chronic obstructive pulmonary disease, 24 (45.6\%) patients with systemic hypertension, $21(40.4 \%)$ patients with previous heart failure, and $1(1.9 \%)$ patient with reverted cardiopulmonary arrest.

In our study, $17(32.7 \%)$ patients had had an acute myocardial infarction (AMI) in the preceding 6 months, 6 (11.5\%) patients had had an AMI between 6 months and 1 year before, $8(15.4 \%)$ had had an AMI between 1 and 2 years before, and 21 (40.4\%) had had an AMI more than 2 years before. The number of preoperative AMI varied as follows: 42 (80.8\%) patients had had 1 previous AMI; 8 (15.4\%) patients had had 2 AMIs; 1 (1.9\%) patient had had 3 AMIs; and 1 (1.9\%) patient had had 4 AMIs.

Preoperative electrocardiography revealed $1(1.9 \%)$ patient with sinus bradycardia, $1(1.9 \%)$ patient with atrial fibrillation, and $1(1.9 \%)$ patient with sustained ventricular tachycardia. The remaining patients had sinus rhythm. Atrioventricular conduction was normal in 49 patients; 2 (3.8\%) patients had first-degree atrioventricular block, and 1 (1.9\%) had complete left bundle-branch block. Of the 52 patients, $1(1.9 \%)$ had atrial septal defect.

Data from the preoperative catheterization were also analyzed. Some patients underwent catheterization in other services, which did not provide us with total access to the results. We were able to obtain the ejection fraction of 47 (89.3\%) patients and the left ventricular dimensions of 43 (81.7\%) patients. The catheterization showed $22(42.3 \%)$ patients with left ventricular akinesia and $30(57.7 \%)$ with dyskinesia. The mean ejection fraction was $45.6 \pm 14 \%$, the left ventricular final diastolic volume was $139 \pm 84 \mathrm{~mL}$, and the left ventricular final systolic volume was $73.7 \pm 50 \mathrm{~mL}$.

In regard to the expansion of coronary artery disease, 6(11.5\%) patients had lesions in 1 vessel, $17(32.7 \%)$ had lesions in 2 vessels, $26(50 \%)$ in 3 vessels, and $3(5.8 \%)$ had lesions in 4 vessels.

The mean duration of extracorporeal circulation was 
87.5 minutes, the shortest being 47 minutes and the longest 147 minutes. The mean duration of ischemia was 60 minutes, the shortest being 30 minutes and the longest 105 minutes. Of this series, 50 (96.2\%) patients underwent myocardial revascularization concomitant with surgery, and $2(3.8 \%)$ patients did not undergo myocardial revascularization. Of those undergoing that procedure (fig. 2), 11 (20.9\%) patients received a mammary artery graft to the anterior descending artery, $29(55.1 \%)$ patients received a saphenous vein bypass graft to the anterior descending artery, $22(41.8 \%)$ received a saphenous vein bypass graft to the right coronary artery, $32(60.8 \%)$ received a saphenous vein bypass graft to the marginal branch, and $10(19 \%)$ received a saphenous vein bypass graft to the diagonal branch. These patients were followed up with clinical examinations, analysis of the medical records, and telephone interviews.

\section{Results}

The characteristics of our sample are similar to those of other studies, with a prevalence of male patients and a mean age over 50 years.

After surgery, we had $4(7.6 \%)$ early deaths in the first postoperative month, $1(1.9 \%)$ death due to low cardiac output, $1(1.9 \%)$ due to respiratory insufficiency, $1(1.9 \%)$ due to arrhythmia, and $1(1.9 \%)$ due to septicemia (tab. I).

The complications in the early postoperative period were as follows: $1(1.9 \%)$ patient had alterations in conduction of the first- and second-degree atrioventricular block type; $4(7.6 \%)$ had atrial fibrillation; $2(3.8 \%)$ had ventricular tachycardia; $5(9.6 \%)$ patients had low cardiac output, 2 due to bleeding and requiring reoperation; and 3 patients had acute left ventricular dysfunction. Of these 3 patients, 2 required the Bio-Pump to leave extracorporeal circulation, and 1 required intraaortic balloon. In the postoperative period, 2 patients had acute respiratory insufficiency.

Postoperative electrocardiography was not performed in $1(1.9 \%)$ patient, and in $41(77.9 \%)$ patients it was identical

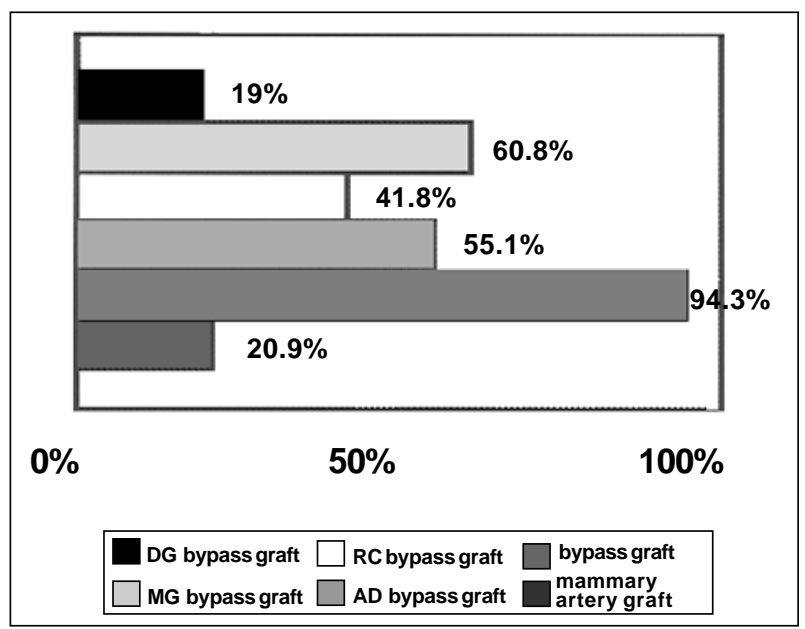

Fig. 2 - Revascularized areas associated with endoventricular patch plasty repair. $\mathrm{DG}$ - diagonal; RC - right coronary; $\mathrm{MG}$ - marginal; $\mathrm{AD}$ - anterior descending.

\begin{tabular}{|c|c|c|c|c|c|}
\hline & $\begin{array}{l}\text { Early deaths } \\
\text { (4 pts) }\end{array}$ & $\begin{array}{l}\text { Survivals } \\
\text { (48 pts) }\end{array}$ & $P$ & $\mathrm{RR}$ & $\begin{array}{c}\text { Confidence } \\
\text { interval }\end{array}$ \\
\hline Mean age (years) & 63 & 57.7 & 0.35 & & \\
\hline NYHA functional class IV ( & (\%) 100 & 45.8 & 0.11 & & \\
\hline $\begin{array}{l}\text { Previous CHF }(\%) \\
>3 \text { impaired coronary }\end{array}$ & 75 & 37.5 & 0.29 & 4.4 & $0.5-39$ \\
\hline arteries $(\%)$ & 75 & 55 & 0.62 & 2.4 & $0.3-21$ \\
\hline More than 2 AMIs (\%) & 0 & 21 & 0.57 & 1.1 & $1-1.2$ \\
\hline EF cat - pre & $46.5( \pm 16.2)$ & $45.6( \pm 14)^{*}$ & 1 & & \\
\hline LVFDV pre & $112( \pm 48)^{* * * *}$ & $139( \pm 84)^{* * *}$ & 0.67 & & \\
\hline LVFSV pre & $50.6( \pm 12)^{* * * *}$ & $73.7( \pm 50)^{* *}$ & 0.4 & & \\
\hline LV dyskinesia (\%) & 100 & 55 & 0.13 & 1.2 & $1-1.3$ \\
\hline LV akinesia (\%) & 0 & 45 & & & \\
\hline $\begin{array}{l}\text { Postop. low } \\
\text { output (\%) }\end{array}$ & 75 & 4.2 & 0.02 & 28 & $3.5-222$ \\
\hline Postop. ARI (\%) & 25 & 2.1 & 0.15 & 8.3 & $1.4-48$ \\
\hline Postop. infection (\%) & 50 & 8.4 & 0.061 & 7.6 & $1.3-44$ \\
\hline $\begin{array}{l}\text { ECC mean duration } \\
(\mathrm{min})\end{array}$ & 99.5 & 85.7 & 0.53 & & \\
\hline $\begin{array}{l}\text { Mean duration } \\
\text { of ischemia (min) }\end{array}$ & 66.7 & 62.5 & 0.72 & & \\
\hline Mammary artery graft $(\%)$ & 25 & 21 & 1 & 1.24 & $0.14-10$ \\
\hline $\begin{array}{l}\text { No revascularization } \\
\text { to } \mathrm{AD}(\%)\end{array}$ & 25 & 22 & & 1.1 & $0.12-9.7$ \\
\hline
\end{tabular}

RR - relative risk; CHF - congestive heart failure; AMI - acute myocardial infarction; EF - left ventricular ejection fraction; LVFDV - left ventricular final diastolic volume; LVFSV - left ventricular final systolic volume; ECC - extracorporeal circulation; ARI - acute respiratory insufficiency; LV - left ventricle; AD - anterior descending artery; * 47 patients; ** 43 patients; *** 3 patients.

to that of the preoperative period. One (1.9\%) patient had $\mathrm{AV}$ conduction disorders, $1(1.9 \%)$ had ventricular extrasystole, $4(7.7 \%)$ had acute atrial fibrillation, $2(3.8 \%)$ had supraventricular tachycardia, and $2(3.8 \%)$ had ventricular tachycardia. In regard to alterations in the ST segment, 1 (1.9\%) patient had alterations in the anterior wall, and the other $(1.9 \%)$ patient had alterations in the inferior wall.

Of our patients, $1(1.9 \%)$ had sepsis and another $(1.9 \%)$ had mediastinal infection.

Forty-seven (89.3\%) patients were discharged in good condition, and $1(1.9 \%)$ persisted with arrhythmia difficult to control.

From July to August 1998, we screened 44 patients through clinical-medical visits or telephone interviews. The mean time between surgery and the interview was 29 months, the shortest being 1 month and the longest 92 months.

Six patients died in a later phase as follows: $2(3.8 \%)$ patients died in the $12^{\text {th }}$ month; $1(1.9 \%)$ died in the $26^{\text {th }}$ month; $1(1.9 \%)$ patient in the $29^{\text {th }}$ month; and $2(3.8 \%)$ patients after the last clinical review, $1(1.9 \%)$ patient in the $86^{\text {th }}$ month, and 1 (1.9\%) patient in the $87^{\text {th }}$ postoperative month (fig. 3 ).

The functional class of the patients reviewed was as follows: 33 (75\%) patients were in class I; 7 (15.9\%) patients were in class II; $2(4.5 \%)$ patients were in class III; and $2(4.5 \%)$ patients were in class IV. Threepatients died in the $12^{\text {th }}, 26^{\text {th }}$, and $86^{\text {th }}$ month without their clinical follow-up. Reports from their relatives indicated that they were asymptomatic until their death. One patient died in the $29^{\text {th }}$ month with important cardiac symptoms.

Twenty patients agreed to undergo postoperative ca- 


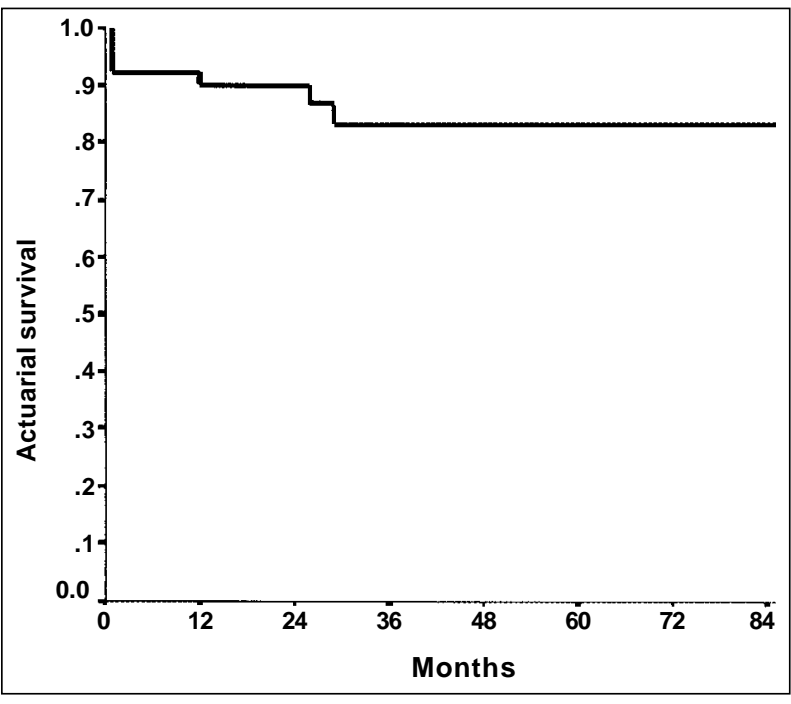

Fig. 3 - Actuarial curve of survival (Kaplan-Meyer) in 84 months.

theterization, and 1 patient had an examination performed in another service comprising only the ejection fraction. The mean time between surgery and the examination was $33.8 \pm 24$ months. The mean ejection fraction of 21 patients was $51.5 \pm 16.7 \mathrm{~mL}$, and the left ventricular final diastolic and systolic volumes of 20 patients were $105 \pm 46 \mathrm{~mL}$ and $57.5 \pm 31 \mathrm{~mL}$, respectively. In regard to the grafts, their patencies were as follows: of the mammary artery grafts to the anterior descending artery, $3(50 \%)$ were patent; of the saphenous vein bypass grafts to the anterior descending artery, $6(60 \%)$ were patent; of the saphenous vein bypass grafts to the right coronary artery, $8(88.9 \%)$ were patent; of the saphenous vein bypass grafts to the diagonal branch, 3 $(60 \%)$ were patent, and of the saphenous vein bypass grafts to the marginal branch, $8(66.7 \%)$ were patent.

\section{Discussion}

Acute myocardial infarction in the left ventricular anterior wall leads to important alterations in left ventricular shape and volume, which do not significantly improve even after successful reperfusion. A loss in the anterior wall and septal contractility occurs, leading to dilation of the nonimpaired muscular mass as an adaptive mechanism to maintain systolic volume. This remodeling causes progressive left ventricular dysfunction and subsequent congestive heart failure. This fact, even in the absence of significant symptoms, focuses attention on surgical repair as a possible treatment for patients with this type of lesion ${ }^{10}$.

Surgical treatment of left ventricular aneurysms is usually indicated in patients with dyskinetic areas. However, the repair technique comprising resection of those areas and reapproximation of the margins reported in $1985^{1}$ does not restore left ventricular morphology and impairs hemodynamic function. According to Jatene ${ }^{7}$, the patient who survives a left ventricular aneurysm should improve with its repair. This concept was the motivation for the constant

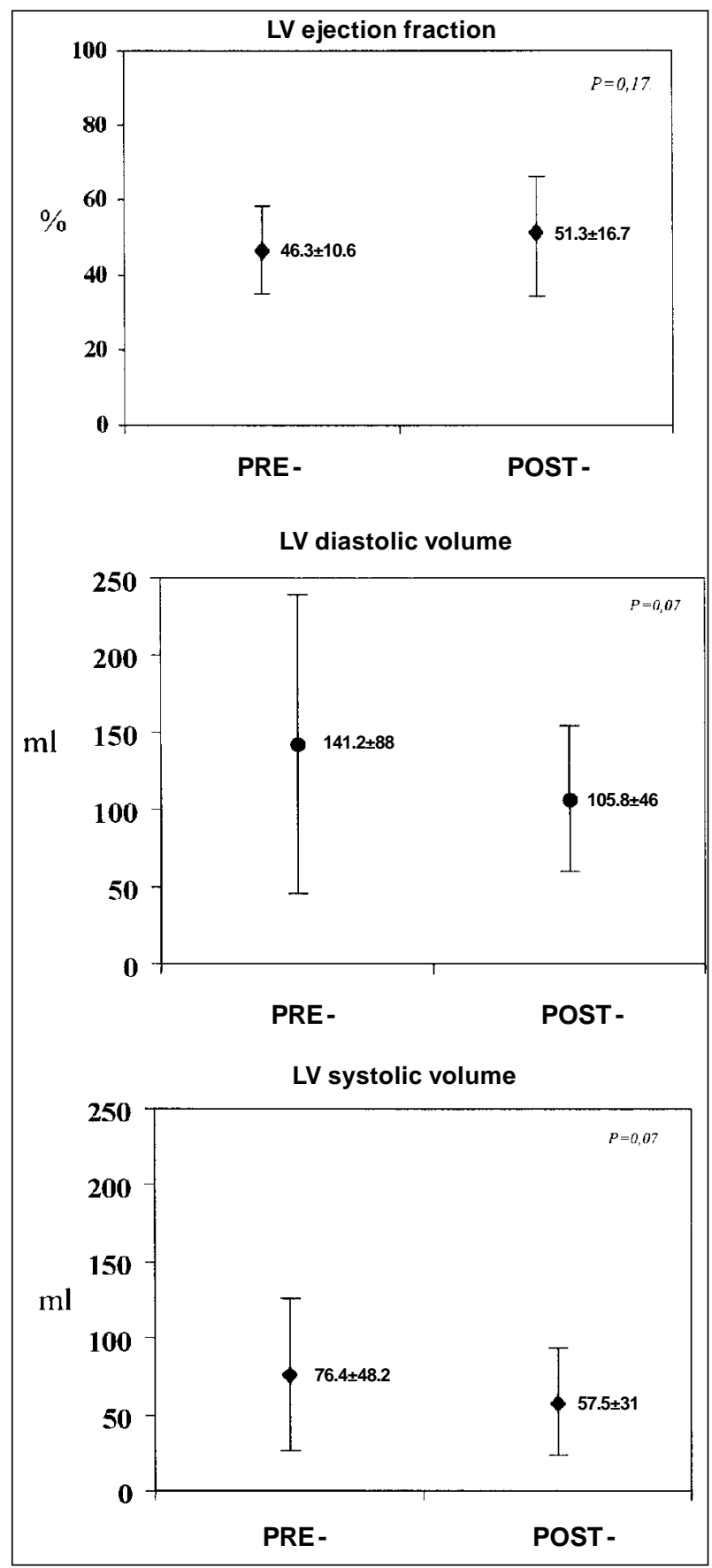

Fig. 4 - Alteration of pre-and postoperative hemodynamic values. LV - left ventricular.

search for ways to refine the technique for correction of left ventricular aneurysms. In 1984, Jatene made an important contribution to the technique of correction of that pathology, emphasizing the relevance of maintaining left ventricular geometry. Dor et al ${ }^{5}$ and Cooley et al ${ }^{1}$ introduced new concepts with the techniques of endoventricular patch plasty repair and endoaneurysmorrhaphy. The technique reported by Cooley et al ${ }^{1}$ and modified with the use of preserved bovine pericardium restores morphology and improves hemodynamic function both in true aneurysms, dyskinetic areas, and in patients with dysfunction due to 
akinetic areas, as reported by Dor et $\mathrm{al}^{5}$. This more physiological technique alters factors that influence the Laplace law, reduces the left ventricular cavity, restores wall pressure to normality, prevents septal paradoxical movements, and brings about an improvement in the hemodynamic and clinical conditions of the patients. Studies have already been published confirming these findings ${ }^{4,5,14-16}$.

The technique reported by Cooley consists of opening the aneurysm area and suturing a Dacron graft between the normal endocardial area and the fibrous area, which is excluded without resecting normal myocardial structures. This surgery allows revascularization of the impaired area.

In a quite different way from that recommended by Cooley, we used a bovine pericardial graft to exclude the akinetic or dyskinetic areas after acute myocardial infarction. This way, we were able to exclude distortions produced in the septum without resecting the viable myocardial wall, allowing the associated revascularization of the anterior descending artery when necessary. The bovine pericardium, which is a more malleable tissue than Dacron is, acts like a cover for the impaired wall, not allowing its dyskinetic movement, therefore increasing left ventricular stroke volume.

We attributed the high index of occlusion of the grafts to the anterior descending artery to the fact that we implanted mammary artery or saphenous vein bypass grafts whenever that artery was patent, independent of its distal bed. Most of the time, the anterior descending artery was located in the fibrous portion of the left ventricular anterior wall, and we intended to use the patent anterior descending artery, even in fibrous areas, as a tube to irrigate the septum through its septal branches.

In conclusion, the repair of left ventricular aneurysms and akinetic areas with the endoventricular patch plasty and endoaneurysmorrhaphy techniques using bovine pericardium showed an increase in left ventricular ejection fraction and a reduction in left ventricular volumes. These values were not statistically significant perhaps because of the low number of patients with pre- and postoperative catheterization (fig. 4). The early mortality rate was low, $7.6 \%$, which is acceptable according to the international literature ${ }^{17-26}$. A significant clinical improvement in the patients was observed in both the dyskinetic areas and akinetic alterations.

\section{References}

1. Cooley DA, Collins HA, Morris Jr GC, Chapman DW. Ventricular aneurysms after myocardial infarction: surgical excision with use of temporary cardiopulmonary bypass. JAMA 1985; 167: 557-60.

2. Prates PR, VitolaD, Santana JR, etal. Técnica de Cooley modificada para correção cirúrgica do aneurisma do ventrículo esquerdo. Arq Bras Cardiol 1991; 56: 219-2.

3. Prates PR, Vitola D, Sant'Anna JRM, etal. Surgical repair of ventricular aneurysms. Texas Heart Inst J 1993; 20: 19-22.

4. Gay WA. Ventricular Aneurism - In: Sabiston D. Textbook of Surgery. $15^{\text {th }}$ edition. Durham: W.B. Saunders Co.; 1997; XIV: 1965-8.

5. Dor V, Sabatier M, Di Donato M, MontiglioF, Toso A, Maioli A. Efficacy of endoventricular patch plasty in large pos infartion akinetic scar and severe left ventricular disfunction comparison with a series of large disknetic scars. J Thorac Cardiovasc Surg 1998; 116: 50-7.

6. Dor V. Advanced therapy in cardiac surgery. In: Decker BC. Endoventricular Patch Plasty Repair for Pos Infarction Severe Left Ventrcular Disfunction. London: Hamilton, 1999; 38: 354-61.

7. Jatene A. Left ventricular aneurismectomy: resection or reconstruction. J Thorac Cardiovasc Surg 1985; 89: 321-31.

8. Cooley DA. Ventricular aneurisms and akinesis. Clev Clin Q 1978; 45: 130-2.

9. Cohen M, Packer M, Gorlin R. Indications of left ventricular aneurismectomy. Current Topics 1983; 67: 717-22.

10. Athanasuleas CL, Stanley AWH, Backberg GD, Dor V, DiDonato M, Blackstone EH and the RESTORE Group. Surgical anterior ventricular endocardial restaration (SAVER) in the dilated remodeled ventricle after anterior myocardial infarction. J Am Coll Cardiol 2001; 37: 1199-209.

11. Santos GG, Haddad V, Avelar SF, et al. Tratamento cirúrgico dos aneurismas do ventrículo esquerdo com reconstrução geométrica: aspectos cirúrgicos e resultados imediatos. Rev Bras Cir Cardiovasc 1991; 6: 116-23.

12. Cooley DA. Ventricular endoaneurysmorraphia results of an improved method of repair. Texas Heart Inst J 1989; 16: 72-5.

13. Hutching GM, Brawley RK. The influence of cardiac geometry on the result of ventricular aneurysms repair. Am J Pathol 1980; 99-221.
14. Rivera R, Delcan JL. Factors influencing better results in operation for post infarction ventricular aneurism. Ann Thorac Surg 1979; 27: 445-50.

15. Di Donato M, Sabatier M, Dor V, Toso A, Maioli M, Fantini F. Akinetic versus dyskinetic postinfarction scar: relation to surgical outcome in patients undergoing endoventricular circular patch plasty repair. J Am Coll Cardiol 1997; 29: 1569-75.

16. Nesralla IA, Sant'Anna, JR, Kalil RA, et al. Resultados tardios com a ressecção de aneurismas ventriculares. Arq Bras Cardiol 1979; 32: 9-13.

17. Coogerman M, Stimon EB, Griepp RB, Shunway NE. Survival and function after left ventricular aneurismectomy. J Thorac Cardiovasc Surg 1995; 69: 321-8.

18. Tudge TL, Olsmer JL, Miells NL. Surgical experience with post infarction ventricular aneurism. South Med J 1979; 70: 29-32.

19. Akins $\mathrm{CW}$. Resection of left ventricular aneurysm during hipotermic fibrilato arrest without aortic oclusion. J Thorac Cardiovasc Surg 1986; 91: 610-8.

20. Brawley RK, Magovern CJ, Gott VL, Donahoo JS, Gardner TJ, Watkins L. Left ventricular aneurysmectomy factors influence post operative results. J Thorac Cardiovasc Surg 1983; 85: 712-7.

21. Burton NA, Stinson EB, Oyer RE, Shunway NE. Left ventricular aneurysm: preoperative risk factors and long term postoperative results. J Thorac Cardiovasc Surg 1979; 77: 65-75.

22. Gosgrove DM, Loop ED, Irarrazaval MS, Groves LK, Taylor PC, Golding LA. Determinants of long term survival after ventricular aneurysmectomy. Ann Thorac Surg 1978; 26: 317-63.

23. Crosby IK, Wellons HA, Martin RP, Schuch D, Muller WH. Employability: a new indication for aneurysmectomy and coronary revascularization. Circulation 1980; 62: 79-83.

24. Harken HA, Horowtz LN, Josephson ME. Comparison of standart aneurysmectomy with directed endocardial resection for the treatment of recurent sustained ventricular tachycardia. J Thorac Cardiovasc Surg 1980; 80: 527-34.

25. Moran JM, Scandon PJ, Nemickas R, Pifarre R. Surgical treatment of post infarction ventricular aneurysm. Ann Thorac Surg 1976; 21: 107-12.

26. Lefemine AA, Govindarajam R, RamaswamyK, BlackH, MaldoffI, Sanella N. Left ventricular resection for aneurysm and akinesia due to coronary artery disease: fifty consecutive patients. Ann Thorac Surg 1977; 23: 461-6. 